\begin{tabular}{c} 
Volume and Issues Obtainable at Center for Sustainability Research and Consultancy \\
Journal of Business and Social Review in Emerging Economies \\
ISSN: 2519-089X (E): 2519-0326 \\
Volume 6: No. 3, 2020 \\
JSRᄃ \\
Journal homepage: www.publishing.globalcsrc.org/jbsee \\
\hline
\end{tabular}

\title{
Impact of Perceived Social Support and Domestic Violence on Mental Health among Housewives
}

\author{
${ }^{1}$ Umbreen Khizer, ${ }^{2}$ Fatima Khurram Bukhari, ${ }^{3}$ Samar Fahd \\ ${ }^{1}$ Assistant Professor, Department of Psychology, Institute of Southern Punjab, Multan \\ ${ }^{2 \& 3}$ Assistant Professor, Department of Applied Psychology, The Islamia University of Bahawalpur, \\ Fatima.khurram@iub.edu.pk
}

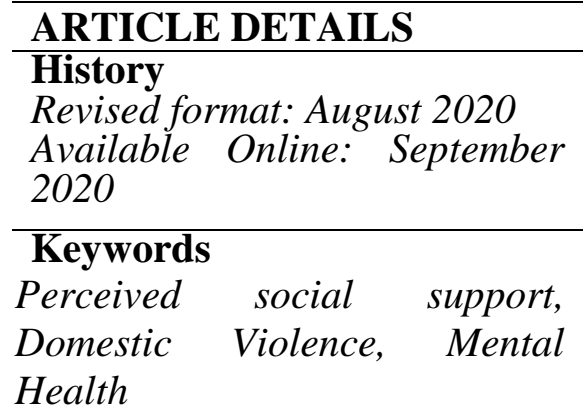

JEL Classification

I1, I3

\begin{abstract}
Given the noteworthy health impacts of social support and domestic violence against women, the current study was directed to research the effect of Perceived Social Support and Domestic Violence on Mental Health among house wives. Sample of the study was consisted of 250 females from Southern Punjab $(n=250)$. Three scales were used to collect the data that included Multidimensional Scale of Perceived Social Support (Jabeen \& Khalid, 2010), Domestic Violence Scale (Hussain, 1998) and Mental Health Inventory (Khan, Hanif \& Tariq, 2015). Data collected from house wives was analyzed through IBM SPSS statistics 20 version. Correlation and Regression was imputed to investigate relationship among study variables. Results indicated that Perceived Social Support, Domestic Violence and Mental Health are significantly correlated with one another. Moreover, Perceived Social Support and Domestic Violence are found to have significant impact on house wives' Mental Health. Furthermore, ANOVA revealed that among various types of violence, housewives are encountering massive degree of emotional abuse as compared to other types of violence.
\end{abstract}

(C) 2020 Center for Sustainability Research and Consultancy Pakistan under a Creative Commons Attribution-NonCommercial-ShareAlike 4.0

Corresponding author's email address: Fatima.khurram@iub.edu.pk

Recommended citation: Khizer, U., Bukhari, F. K. \& Fahd, S. (2020). Impact of Perceived Social Support and Domestic Violence on Mental Health among Housewives. Journal of Business and Social Review in Emerging Economies, 6(3), 1153, 1157

\section{Introduction}

Keyes (2002) defined mental health as a syndrome of symptoms of hedonia and positive functioning, operationalized by measures of subjective well-being - individuals' perceptions and evaluations of their lives and the quality of their functioning in life. Keyes (2012) specified that mental health is a mixture of emotional, psychological, and social well-being. Swami (2007) referred that without healthy mental state a person cannot attain contentment in life. The World Health Organization (WHO) sees mental health as "a condition of well-being in which the person identifies his own potential, can work industriously and profitably, can handle the regular life stresses and is capable of providing input to her or his society". 
Comparative studies have demonstrated that individuals with low social help express additional subclinical indications of uneasiness and dejection as contrast with those individuals who have high social help around them (Barrera, 1986; Cohen \& Willis, 1985). In addition, little social help additionally offer ascend to complex rates of mental issue than those with high help, including alarm issue, posttraumatic stretch issue, social fear, dysthymic clutter, significant depressive issue, and dietary issues. People with schizophrenia who have low social support exhibit more warning sign of the disorder. Furthermore, more ideation, and more alcohol and (illicit and prescription) drug problems has been associated with people with low support.

Abusive behavior at home (additionally named residential maltreatment or family viciousness) is a collective pattern of activities that encompasses violence or abuse by one person usually (a man), against another person, (a woman) in a household situation, like in marriage or living relationship. It will be called IPV (Intimate Partner Violence) when done by a partner in an intimate relationship towards the other partner, and could happen in between former spouses or partners, heterosexual or homo sexual relationships(Kasturirangan, 2008).

Domestic violence is widespread across Pakistan but the condition in Punjab is terrible. An annual Report (The Aurat Foundation, 2009) claimed (as cited in Ashraf, Abrar-ul-Haq, \& Ashraf, 2017) that in a year, 608 cases were reported of domestic violence, out of them 271 cases were occurred in Punjab, 134 cases were reported in Sindh, 163 cases in the NWFP, 22 cases were filed in Baluchistan and 18 cases were filed in Islamabad. As per a WHO report, domestic violence is the most continuous savagery submitted against females and causes genuine results.domestic violence passings frequently stay undetected because of the disappointment of the framework to record the particular reason for death and furthermore because of the quantity of passings brought about by self-destruction and medication misuse following domestic violence. Aggressive behavior at home demonstrates any fierce conduct submitted against somebody by a relative that causes physical, mental, social, monetary and sexual mischief and prompts injury, demise, mental injury, obstructed advancement and hardship (Sinha, Mallik, Sanyal, Dasgupta, Pal, Mukherjee, 2012).

However, there is scarcity of empirical evidences that assess the impact of perceived social support and domestic violence among house wives. Hence, the current study is designed to capture the level of mental health influenced by the perceived social support and domestic violence among Pakistani house wives.

\subsection{Objectives of the study}

1. To measure the impact of social support on mental health of house wives.

2. To study the impact of domestic violence on mental health of house wives.

3. To check the correlation between perceived social support and domestic violence.

4. To study the magnitude of different types of violence among housewives.

\subsection{Hypotheses of the Study}

1. There would be a significant positive effect of perceived social support on mental health among housewives.

2. There would be a negative effect of domestic violence on mental health among housewives.

3. There would be a negative correlation between perceived social support and domestic violence among housewives.

4. Emotional violence would be higher as compared to other types of violence.

\section{Method}

\subsection{Sample}

The sample of the study was the violence facing housewives in rural areas of Southern Punjab. Women facing violence were screened through interviews. Sample of the study was consist of 250 females (N=250). Purposive sampling technique was used for the selection of the participants.

\subsection{Instruments}

1. Domestic Violence Scale: This scale was developed by Hussain (1998). The scale included a total of 35 items which consists of 5 subscales categories: physical violence, emotional violence sexual violence social violence, 
economical violence. All items are negatively phrased; high scores indicate more experience of domestic violence while low scores show lesser exposure to domestic violence. The reliability of total score is .83, physical (.69), emotional (.77), sexual (.63), social (.73) and economical (.71).

2. Multidimensional Scale of Perceived Social Support: the scale was developed by Zimet, Dahlem, Zimet \& Farley, (1988). It was utilized to identify the source of help from 3 sources: Family, Friends, and huge other. The reliability of aggregate scale was .88. Score running from 1 to 2.9 could be viewed as low help; a score of 3 to 5 could be viewed as moderate help; a score from 5.1 to 7 could be viewed as high help.

3. Mental Health Inventory: Urdu Translation of this scale was used to measure mental condition of women facing domestic violence. The scale comprises of 38 items. It comprised of two subscales: Psychological Distress included 22 items and Psychological Well-being comprising of 16 items. MHI was evaluated on 6-point rating scale extending from $1=$ all of the time to $6=$ none of the time. MHI demonstrated sufficient reliability and solid interior consistency running from .83 to .96 (Stead, Shanahan, \& Neufeld, 2010).

\subsection{Procedure}

The research was led through the use of three questionnaires Domestic Violence Scale (DVS), Multidimensional Scale Perceived Social Support (MSPSS) and Mental Health Inventory (MHI) to measure the impact of Perceived Social Support and Domestic Violence on Mental Health of House wives. The scales were administered in Urdu language. General instructions were given to the respondents related to the purpose and time of task. They were asked to go through the instructions provided before each scale and then start responding. After data collection, statistical analysis was conducted in order to test the hypothesis.

\section{Results and Discussion}

Data collected from house wives to assess level of mental health influences by perceived social support and domestic violence was analysed using correlation, regression and Analysis of variance.

Table 1

Standard regression model showing impact of Multidimensional Perceived Social Support on Mental Health Inventory.

\begin{tabular}{llllll} 
Variable & B & Std. Error & Beta & t & P \\
\hline MHI & 89.63 & 3.25 & & 27.55 & .000 \\
MPSS & .35 & .07 & .29 & 4.88 & .000
\end{tabular}

$\mathrm{R}^{2}=.088$, Adjusted $\mathrm{R}^{2}=.084, \mathrm{~F}=23.900, \mathrm{p}<.000$

First hypothesis was that there would be a significant positive effect of perceived social support on mental health among housewives. Simple linear regression was carried out to find the effect of perceived social support on mental health. Result discloses that dependent variable of mental health is $88 \%$ explained by the independent variable of perceived social support as indicated by the value of $\mathrm{R}^{2}=.088$. A significant $\mathrm{F}$-value $(\mathrm{F}=23.900, \mathrm{p}<.000)$ also shows that model significantly explains the outcome variable. The t-value is also an indicative of perceived social support. It has significant effect on mental health.

Table 2

Standard regression model showing impact Domestic Violence Scale on Mental Health Inventory $(\mathrm{N}=250)$

\begin{tabular}{lccccc} 
Variable & B & Std. Error & Beta & $\mathrm{t}$ & $\mathrm{P}$ \\
\hline MHI & 139.57 & 4.29 & & 32.53 & .000 \\
DVS & -.48 & .059 & -.466 & -8.28 & .000
\end{tabular}

$\mathrm{R}^{2}=.217$, Adjusted $\mathrm{R}^{2}=.214, \mathrm{~F}=68.69, \mathrm{p}<.000$

Second hypothesis was that there would be an effect of domestic violence on mental health among housewives. Simple linear regression was carried out to find the effect of domestic violence on mental health. Result explains that dependent variable of mental health is $21 \%$ explained by the independent variable of domestic violence as indicated 
by the value of $\mathrm{R}^{2}=.217$. A significant $\mathrm{F}$-value $(\mathrm{F}=68.69, \mathrm{p}<.000)$ also represents that model significantly explains the outcome variable. The t-value also indicates that domestic violence has significant effect on mental health.

Table 3

Correlation among Multidimensional Perceived Social Support and Domestic Violence Scale (N=250)

\begin{tabular}{ccc}
\hline & MSPSS & DVS \\
\hline MSPSS & 1 & $-.539^{* *}$ \\
DVS & $-.539^{* *}$ & 1 \\
& & \\
\hline
\end{tabular}

Note: **. At the 0.01 level (2-tailed) correlation is significant

Third hypothesis was that there would be a negative correlation among perceived social support and domestic violence. In order to test this hypothesis Pearson correlation was used. The results suggest that there is a significant negative correlation between perceived social support and domestic violence as $r=-.539$. Therefore, it is concluded that housewives facing domestic violence have received less social support.

Table 4

One-way ANOVA analysis for Economical Violence Scale and other types of Violence $(\mathrm{N}=250)$

\begin{tabular}{llllll}
\hline & Sum of Squares & Df & Mean Square & F & Sig. \\
\hline PVS & & & & & \\
Between Groups & 1780.752 & 58 & 30.703 & 8.597 & .000 \\
Within Groups & 682.148 & 191 & 3.571 & & \\
Total & 2462.900 & 249 & & & \\
EMVS & & & & 12.507 & .000 \\
Between Groups & 5222.115 & 58 & 90.036 & & \\
Within Groups & 1375.009 & 191 & 7.199 & & \\
Total & 6597.124 & 249 & & 4.477 & .000 \\
SEVS & & & & \\
Between Groups & 864.911 & 58 & 14.912 & & \\
Within Groups & 636.213 & 191 & 3.331 & & .000 \\
Total & 1501.124 & 249 & & & \\
SVS & & & & \\
Between Groups & 3386.547 & 58 & 58.389 & & \\
Within Groups & 1121.329 & 191 & 5.871 & & .000 \\
Total & 4507.876 & 249 & & & \\
EVS & & & & & \\
Between Groups & 3635.562 & 58 & 62.682 & & \\
Within Groups & 1446.362 & 191 & 7.573 & & \\
Total & 5081.924 & 249 & & & \\
\hline
\end{tabular}

Fourth hypothesis was that emotional violence would be higher than other types of violence. Anova was used in order to assess this assumption. The significant difference among emotional violence and other types of violence was shown by ANOVA results. Where emotional violence $\mathrm{F}(58,191)=12.507, \mathrm{p}=(.000<0.05)$. Therefore, this hypothesis is accepted.

\section{Conclusion}

The selected target population of the study was housewives facing violence in rural areas. Sample of the study was consisted on 250 females from Southern Punjab $(\mathrm{N}=250)$. The findings from this investigation features the significance of this research that gives prospect to abused women to show their feelings and sharing their stories. The main purpose of this sharing is to better understand their violence experiences. The outcomes confirmed the first hypothesis and concluded perceived social support have significant positive effect on mental health among housewives. The second hypothesis concluded that there is an effect of domestic violence on mental health of housewives and mental health of housewives are disturbed and it was explored that domestic violence and abuse are 
related with an expanded danger of psychological illness. Third hypothesis was there is a negative correlation between perceived social support and domestic violence among housewives. The study discovered that for the most part violence disclosure was debilitated by the social conviction of disguising their marriage matters at all cost, by contemplations of defending the kid's advantages, by sentiments of self-fault and blame and in addition the ladies' absence of learning on abusive behavior at home assets. Fourth hypothesis outcome was emotional violence is higher as compare to other types of violence as study revealed that housewives encountering large amount of emotional abuse as compare to other types of violence.

\section{References}

Ashraf, S., Abrar-ul-Haq, M., \& Ashraf, S. (2017). Domestic violence against women: Empirical evidence from Pakistan. Pertanika Journal of Social Sciences \& Humanities, 25(3), 1401-1418.

Barrera, M. (1986). Distinctions between social support concepts, measures, and models. American journal of community psychology, 14(4), 413-445.

Cohen, S., \& Wills, T. A. (1985). Stress, social support, and the buffering hypothesis. Psychological bulletin, 98(2), 310.

Hussain, S. (1998). Domestic violence: Myths and reality unpublished M.phil Dissertation. Islamabad National Institute of Psychology Quaid-i-Azam University.

Jibeen, T., \& Khalid, R. (2010). Development and preliminary validation of multidimensional acculturative stress scale for Pakistani immigrants in Toronto, Canada. International Journal of Intercultural Relations, 34(3), $233-243$.

Kasturirangan, A. (2008). Empowerment and programs designed to address domestic violence. Violence Against Women, 14(12), 1465-1475.

Keyes, C. L. (2012). The mental health continuum: From languishing to flourishing in life. Journal of health and social behavior, 207-222.

Keyes, C. L. (2002). The mental health continuum: From languishing to flourishing in life. Journal of health and social behavior, 207-222.

Khan, M. J., Hanif, R., \& Tariq, N. (2015). Translation and validation of mental health inventory. Pakistan Journal of Psychological Research, 65-79.

Sinha, A., Mallik, S., Sanyal, D., Dasgupta, S., Pal, D., \& Mukherjee, A. (2012). Domestic violence among ever married women of reproductive age group in a slum area of Kolkata. Indian journal of public health, 56(1), 31.

Stead, R., Shanahan, M. J., \& Neufeld, R. W. (2010). "I'll go to therapy, eventually": Procrastination, stress and mental health. Personality and individual differences, 49(3), 175-180.

Swami, V., Chamorro-Premuzic, T., Sinniah, D., Maniam, T., Kannan, K., Stanistreet, D., \& Furnham, A. (2010). General health mediates the relationship between loneliness, life satisfaction and depression. Social psychiatry and psychiatric epidemiology, 42(2), 161-166.

Veit, C. T., \& Ware, J. E. (1983). The structure of psychological distress and well-being in general populations. Journal of consulting and clinical psychology, 51(5), 730.

Zimet, G. D., Dahlem, N. W., Zimet, S. G., \& Farley, G. K. (1988). The multidimensional scale of perceived social support. Journal of personality assessment, 52(1), 30-41. 